\title{
New species of Ptychozoon (Sauria: Gekkonidae) from the Nicobar Archipelago, Indian Ocean
}

\author{
INDRANEIL DAS ${ }^{1} \&$ S. P. VIJAYAKUMAR ${ }^{2}$ \\ ${ }^{1}$ Institute of Biodiversity and Environmental Conservation, Universiti Malaysia Sarawak, 94300, Kota Samarahan, Sarawak, \\ Malaysia.E-mail: hamadryad2004@hotmail.com \\ ${ }^{2}$ Centre for Ecological Sciences, Indian Institute of Science, Bangalore 12, India. E-mail: vijay_rhaco@yahoo.com \\ ${ }^{3}$ Corresponding Author
}

\begin{abstract}
A new species of Ptychozoon is described from the central portion of the Nicobar Archipelago, Bay of Bengal, India. It has been formerly referred to P. kuhli, a species widely distributed in Sundaland. Ptychozoon nicobarensis sp. nov. reaches an SVL of $100.3 \mathrm{~mm}$, and is diagnosable from congeneric species in showing the following combination of characters: dorsum with a tan vertebral stripe, lacking dark transverse bars; supranasals in contact; cutaneous expansions on sides of head; absence of predigital notch in preantebrachial cutaneous expansion; imbricate parachute support scales; four irregular rows of low, rounded enlarged scales on dorsum; 20-29 scales across widest portion of tail terminus; three indistinct chevrons on dorsum; 7-11 pairs of preanal pores; femoral pores absent; tail with an expanded terminal flap and weak lobe fusion at proximal border of tail terminus. The curious distribution of the new species, centred around the central Nicobars is speculated to be the result of competition with and/or predation by large gekkonid species, to the north (Gekko verreauxi) and south (G. smithii) of the group of islands occupied by the new Ptychozoon from the central Nicobars.
\end{abstract}

Key words: Ptychozoon, systematics, new species, Nicobar Archipelago, India

\section{Introduction}

The genus Ptychozoon was established by Kuhl \& van Hasselt (1822) for Lacerta homalocephala Creveld, 1809. Stejneger (1902) found that the name was preoccupied by Lacerta homalocephala Suckow, 1798 and provided the replacement name Ptychozoon kuhli. The holotype was in the collection of Dr. Creveld at the time of description, and is untraced at present; the type locality was not specified in the original description. Gekkonid lizards of the genus Ptychozoon are essentially Sundaic in distribution: of the six species currently recognised (Kluge, 2001), four (horsfieldii Gray, 1827, kuhli Stejneger, 1902, lionotum Annandale, 1905, and rhacophorus Boulenger, 1899) have their distribution on Sundaland. Two additional species occur extralimital to this region- one each in Indochina (Ptychozoon trinotaterra Brown, 1999) and the Philippines (Ptychozoon intermedium Taylor, 1915). Members of the genus are diagnosable from other Asian gekkonid genera (except Luperosaurus), in showing the following characters: medium-sized to large (SVL to $107.8 \mathrm{~mm}$ ); cutaneous folds on limbs and on sides of body; digits dilated and strongly webbed, with undivided transverse lamellae; terminal phalanges united with dilated portion to its distal end and extending beyond; inner digit clawless; dorsal scales small, typically intermixed with large tubercles; pupil vertical and males with preanal and femoral pores (Brown et al., 1997; Smith, 1935: 117; Taylor, 1963: 806). The political range encompassed by the distribution of members of the genus Ptychozoon includes the Nicobar Archipelago, north-eastern India, Myanmar, Thailand, Cambodia, Vietnam, Peninsular Malaysia, Sumatra, Borneo and the Philippines (Brown et al., 1997; Grismer et al., 2008). 